\title{
El Partido Liberal MEXICANO Y LA INSURRECCIÓN REVOLUCIONARIA DE I9O6 EN ChiHuahua
}

MIGUEL ÁNGEL RAMÍREZ JAHUEY ${ }^{1}$

\section{RESUMEN}

1 esde su fundación, el Partido Liberal Mexicano desplegó una intensa actividad revolucionaria con el objetivo de derrocar la dictadura de Porfirio Díaz. El estado de Chihuahua se convirtió en uno de los principales baluartes de apoyo del partido, debido a sus condiciones sociales, políticas y económicas, lo cual le permitió a este grupo priorizar su actividad en dicha región. En 1906 se llevó a cabo el primer intento insurreccional organizado por el Partido Liberal Mexicano, que tenía como objetivo primordial capturar Ciudad Juárez y consolidar allí la revolución. En el presente artículo se analiza el desarrollo del mismo.

Palabras clave: Partido Liberal Mexicano, 1906, Chihuahua, revolución, frontera norte.

\section{ABSTRACT}

Since its foundation the Partido Liberal Mexicano has deployed an intense revolutionary activity with the aim of overthrowing

1 Universidad Nacional Autónoma de México, México. Correo electrónico: miguelskarj@ gmail.com. 
the dictatorship of Porfirio Díaz. The state of Chihuahua became one of the main support bastions of this party due to its social, political, and economic conditions which allowed this group to prioritize its activity in that region. In 1906 the first insurrectional attempt organized by Partido Liberal Mexicano was carried out whose main objective was to capture Ciudad Juárez and consolidate the revolution there. In the present article its development is analyzed.

Keywords: Partido Liberal Mexicano, 1906, Chihuahua, revolution, Northern border.

\section{INTRODUCCIÓN}

Se ha establecido el 20 de noviembre de 1910 como la fecha oficial del inicio de la Revolución Mexicana, pues fue ese día el elegido por Francisco I. Madero para levantarse en armas contra la dictadura de Porfirio Díaz. No obstante, la historiografía contemporánea ha resaltado la importancia que tuvo en la conformación de la revolución la existencia de una oposición política y militar previa a esa fecha, encabezada por el Partido Liberal Mexicano (PLM), pues desde su fundación en 1905 esta agrupación buscó por medio de la organización de clubes políticos y la insurrección armada derrocar al gobierno mexicano. ${ }^{2}$ En Chihuahua, particularmente, el PLM tuvo una influencia muy destacada debido a las condiciones políticas y sociales del estado, pero también por su cercanía geográfica con Estados Unidos, país en el cual se encontraban exiliados los principales dirigentes del partido y desde donde llevaban a cabo su actividad política.

El pLM encontró en Chihuahua una base social que hizo eco de sus reivindicaciones y permitió que se establecieran importantes núcleos de apoyo que cobijaron a la organización en su lucha contra la dictadura entre 1906 y 1908. En las próximas páginas explicaremos cómo se conformó en Chihuahua esta base social

2 Entre los trabajos más destacados que estudian a esta organización figuran: Hart, 1980; Cockcroft, 1981; Hernández Padilla, 1988; Lloyd, 1988; Torres Parés, 1990; Bartra, 1994; Esparza Valdivia, 2000; Trejo, 2005. 
El Partido Liberal Mexicano y la insurrección Revolucionaria de 1906...

de simpatizantes que dio como resultado un primer intento insurreccional en 1906, adelantándose cuatro años a la revolución maderista de 1910, con Ciudad Juárez como punta de lanza de un proyecto político-social que tenía como fin derrocar la dictadura de Porfirio Díaz.

\section{NACIMIENTO DEL PARTIDO LIBERAL MEXICANO}

A principios del siglo xx, México experimentó una ola de descontento entre varios sectores de la población, debido a las medidas políticas y sociales implementadas durante la extendida administración de Porfirio Díaz. Periodistas, estudiantes, maestros e intelectuales de la clase media urbana, así como campesinos y comerciantes de distintas procedencias geográficas, empezaron a levantar la voz en contra de un sistema que se alejaba cada vez más de los principios liberales que caracterizaron a la generación de la Reforma. Este malestar fue canalizado por los esfuerzos del ingeniero Camilo Arriaga, presidente del Club Liberal "Ponciano Arriaga”, quien organizó en San Luis Potosí dos congresos entre 1901 y 1902, a los que se dieron cita los opositores del régimen con el objetivo de establecer una articulación política y discutir la refundación de un Partido Liberal que reivindicara los principios de la Constitución de 1857, que ellos consideraban eran flagrantemente violados por la dictadura, al tolerar la creciente injerencia de la Iglesia en asuntos políticos.

De esta organización en San Luis Potosí, se desprendieron nuevos grupos y clubes que se diseminaron a lo largo y ancho del país para trabajar de manera regional en conformación de la oposición política hacia el gobierno mexicano. Algunos de estos clubes iban más allá de la exigencia al respeto de los principios liberales, pues también comenzaron a cuestionar las problemáticas sociales del régimen de Porfirio Díaz, como el caso del Club "Redención" de la Ciudad de México, entre cuyos miembros estaban los hermanos Jesús y Ricardo Flores Magón, dos escritores que ejercieron una influencia notable en la prensa a través de su periódico Regene- 
ración, en cuyos artículos denunciaban la mala administración de la justicia porfirista. ${ }^{3}$

Pero no pasó mucho tiempo para que el gobierno actuara en contra de estas voces y plumas críticas. Varios clubes liberales fueron clausurados violentamente en todo el país y sus dirigentes fueron encarcelados como escarmiento a su activismo en contra de la dictadura, entre ellos, los propios hermanos Flores Magón, quienes en 1903 pasaron seis meses en la cárcel de Belén por su actividad periodística. ${ }^{4}$ Luego de cumplir su sentencia, los más destacados dirigentes liberales decidieron abandonar el país ante la imposibilidad de ejercer libremente su labor informativa con plena seguridad, buscando nuevos horizontes para continuar su lucha opositora en contra de la dictadura.

A inicios de 1904, las direcciones de los grupos opositores que conformaban el Club Liberal "Ponciano Arriaga" y el Club "Redención", decidieron exiliarse en Estados Unidos; los liberales confiaban en que sus actividades se podrían desarrollar sin mayores inconvenientes en una nación donde la libertad de prensa garantizaba que la propaganda de sus ideas fuera efectiva y sin obstáculos. Los primeros en cruzar la frontera fueron los hermanos Ricardo y Enrique Flores Magón (Jesús, el hermano mayor, había decidido abandonar la lucha política luego de su encarcelamiento) y Santiago de la Hoz, a quienes posteriormente se les sumaron Camilo Arriaga, Librado Rivera, Antonio Irineo Villarreal, y los primos Juan y Manuel Sarabia. En conjunto, estos liberales formaban el núcleo original del Club Liberal "Ponciano Arriaga", fundado en San Luis Potosí en 1900; no obstante, pronto se hicieron evidentes una serie de diferencias entre los planteamientos ideológicos de Ricardo Flores Magón y Camilo Arriaga, que se habían iniciado desde la Ciudad de México, ${ }^{5}$ pues el primero sostenía que la lucha en contra de la dictadura tenía que enmarcarse en un contexto

\footnotetext{
3 Bartra, 1994, p. 21.

4 Cockcroft, 1981, pp. 106-110; Torres Parés, 1990, p. 25.

5 Arriaga se distanció del Club "Redención", luego de que esta agrupación atacara directamente la reelección de Porfirio Díaz, por considerar que el radicalismo de Ricardo Flores Magón era "un esfuerzo personalista que afectaba la unidad del club [Ponciano Arriaga]". Torres Parés, 1990, p. 25.
} 
más amplio al de la oposición política legal hasta ese momento desarrollada y que dentro de los objetivos para la creación de un futuro Partido Liberal, se debían incluir las exigencias de los trabajadores urbanos y rurales; la idea de Flores Magón era conformar un partido que no solo asumiera una línea meramente política, como lo proponían Arriaga y los hombres cercanos a este, sino que fuera más allá de los marcos jurídicos de la Constitución de 1857, para llevar a cabo amplias reformas sociales y combatir las causas de la pobreza y la desigualdad generadas por la dictadura de Porfirio Díaz.

Pero Flores Magón fue más allá al argumentar que una revolución violenta con fines socioeconómicos, debía ser el objetivo principal del Partido Liberal, pues en su concepto esta era la única vía para derrocar al gobierno mexicano. Arriaga rechazó dicha postura, aunque sin argumentos suficientes para combatir el entusiasmo de las posiciones avanzadas de Ricardo, por lo que fue relegado de la organización, con lo cual el ala moderada quedó excluida al escindirse del naciente partido. A partir de este momento, las prioridades del núcleo radical cohesionado en torno a la persona de Ricardo Flores Magón fueron conspirar, sumar simpatizantes, hacerse de recursos económicos y construir una dirección política y programática sólida para llevar a cabo su misión. Este grupo comenzó a formular los planes para preparar las bases del PLM, a través de la reorganización del movimiento liberal que había nacido en San Luis Potosí en 1901.

Al mismo tiempo, los exiliados mexicanos decidieron continuar con su labor periodística con la seguridad de que en el territorio estadounidense se garantizaba constitucionalmente la libertad de imprenta y de expresión. Después de una serie de avatares económicos, Regeneración, la herramienta de difusión más poderosa con la que contaban desde los días de lucha en la Ciudad de México, apareció finalmente el 5 de noviembre de 1904 en San Antonio, Texas, lugar en donde los liberales se establecieron al cruzar la frontera. Regeneración no solo sirvió para reactivar la propaganda liberal, sino que también fue un catalizador de la prensa de oposición en la frontera norte, ya que en torno a este se- 
manario surgieron otras publicaciones promovidas por militantes y adictos liberales, quienes se sumaron al esfuerzo de los exiliados por articular nuevas redes de comunicación e información, con la finalidad de que estas funcionaran como un "agitador y organizador colectivo" mediante el cual se expandiera la voz de lucha a todos los rincones posibles. ${ }^{6}$ Una red de distribución clandestina de Regeneración comenzó a consolidarse en el sur de Estados Unidos, pero también al interior de la República Mexicana, donde el semanario llegaba de diversas maneras gracias al apoyo de comerciantes instalados en la frontera y de los trabajadores ferrocarrileros que se encargaban de transportarlo para que circulara en el país. Pronto Regeneración comenzó a influir no solo en la población mexicana de la frontera, sino también del interior de la República Mexicana. Al ser un país mayoritariamente analfabeta, Regeneración penetró entre los obreros y campesinos por medio del oído: si una persona sabía leer, esta lo hacía en voz alta para que los demás escucharan el mensaje, el cual a su vez era transmitido de voz en voz con el objetivo de difundir la noticia.

Hacia febrero de 1905 los liberales se trasladaron de San Antonio, Texas, a San Luis, Misuri, con el propósito de despistar a los espías del gobierno mexicano, el cual había iniciado una intensa campaña de persecución y hostigamiento en contra de los llamados "revoltosos" en Estados Unidos, para desarticular su cada vez más creciente influencia entre la población de origen mexicano. Un ambiente de convulsión se respiraba en esta ciudad, donde una gama de exiliados provenientes de distintos países confluían en un espacio común; socialistas, anarquistas y activistas de agrupaciones obreras como Industrial Workers of the World, hicieron

6 Bartra, 1994, p. 18. En la frontera méxico-estadounidense surgieron o se sumaron al impulso de Regeneración periódicos como La Bandera Roja y Resurrección, de Rafael Sáenz; El Defensor del Pueblo, de Manuel Sarabia; Reforma, de Tomás Sarabia; El Obrero, de Teresa Villarreal; El Liberal, de Amado Gutiérrez; 1810, de Crescencio Villarreal Márquez; y La Reforma Social, de Lauro Aguirre, todos ellos publicados en el estado de Texas. Dichos impresores estaban en estrecha colaboración con los editores de Regeneración, así como con otros periódicos de habla inglesa (Wickstrom, 2001, p. 259).

7 El término "revoltosos" se utilizó frecuentemente para identificar a los agitadores y revolucionarios mexicanos que operaban en Estados Unidos. Particularmente, se identificó así a los también llamados "magonistas". 
de San Luis, Misuri, un centro de actividad política de izquierda, al cual se sumaron los integrantes del PLm. ${ }^{8}$

El 28 de septiembre de 1905 finalmente quedó constituida la Junta Organizadora del PLm (en adelante Joplm), en la cual Ricardo Flores Magón figuraba como presidente, Juan Sarabia como vicepresidente, Antonio I. Villarreal como secretario, Enrique Flores Magón como tesorero y los vocales fueron Manuel Sarabia, Librado Rivera y Rosalío Bustamante. Al iniciar 1906, la Joplm se abocó a realizar un trabajo de unificación de sus militantes, a través de una nutrida correspondencia con los miembros activos del interior de la República Mexicana y de la frontera estadounidense, con dos objetivos definidos: conocer las opiniones de sus simpatizantes acerca del país en materia social, política y económica, y organizar una red de apoyo insurreccional para efectuar una revolución armada en contra de la dictadura.

Las opiniones vertidas por los simpatizantes liberales, a través de la correspondencia, les permitió a los miembros de la JopLM reunir material de primera mano de distintos puntos geográficos, para esbozar un documento que planteaba una serie de propuestas encaminadas a solucionar las grandes problemáticas de México, un ambicioso y extenso plan en torno al cual los miembros del partido buscarían articular la lucha en contra de la dictadura.

El 1 de julio de 1906 la Joplm dio a conocer en San Luis, Misuri, el Programa del PLm, ${ }^{9}$ cuyo objetivo principal era aniquilar la estructura oligárquica del Estado y los cimientos que lo apuntalaban, el ejército, los gobiernos estatales, los poderes de la unión, los terratenientes y los banqueros, para crear un poder democrático, justiciero en materia social, nacionalista y antiimperialista. La democratización del sistema político, la participación inclusiva de la población en los asuntos del gobierno, la desaparición de los jefes políticos, la eliminación del servicio militar obligatorio, el acceso a la educación y una serie de reivindicaciones agrarias y obreras como el salario mínimo y la jornada máxima de trabajo, fueron las

8 Barrera Fuentes, 1973, p. 159; Torres Parés, 1990, p. 30.

9 El Programa del PLM, se puede consultar en línea a través del portal del archivo electrónico de Ricardo Flores Magón: http://archivomagon.net/wp-content/uploads/e3n11.pdf 
principales demandas que integraron un proyecto de propuestas sociales vanguardistas, hasta el momento inéditas en la historia de México y del mundo (la Revolución rusa estaba a once años de distancia, al igual que la promulgación de la Constitución mexicana de 1917, que incluyó una legislación progresista en materia social). Por ello, los miembros del PLM se propusieron imprimir doscientos cincuenta mil ejemplares de su Programa para distribuirlo masivamente a través de la red de Regeneración en México y la frontera con Estados Unidos, con la intención de ganar la mayor cantidad de adeptos para su causa. ${ }^{10}$

Paralelamente a la preparación del Programa del PLM, los miembros de la JOPLM fraguaron un ambicioso proyecto para promover levantamientos armados en todo el territorio mexicano. Desde 1905 Ricardo Flores Magón había manifestado a sus correligionarios de mayor confianza sus planes profundos:

A nosotros nos parece que debemos hacer trabajos secretos para ir preparando la revolución [...] Trabajemos para la reorganización del Partido Liberal en público como lo estamos haciendo, y en lo privado pongámonos de acuerdo con los hombres de corazón bien puesto que haya, para hacer la revolución. ${ }^{11}$

Para los liberales era el momento de acompañar la palabra con la acción armada: "Cada lector de Regeneración - decía Ricardo Flores Magón - debe ser un soldado de la revolución, cada miembro del Partido Liberal Mexicano debe ser un agente de armas y parque; el día de exterminar al tirano ha llegado, pueblo ja las armas!" ${ }^{12}$

10 Delgado González, 1991, p. 38.

11 Flores Magón, 2001, pp. 143-144.

12 Citado por Valadés, 2010, p. 6. 
El Partido Liberal Mexicano y la insurRección Revoludionaria de $1906 \ldots$

\section{LA CONFORMACIÓN DE LA BASE SOCIAL DEL PLM EN LA FRONTERA MÉXICO-ESTADOUNIDENSE}

El 1 de junio de 1906, un mes antes de la promulgación del Programa del PLM, la JOPLM dio a conocer a los miembros de su red secreta de simpatizantes una serie de "Instrucciones Generales a los Revolucionarios", ${ }^{13}$ en las que conminaba a los grupos pelemistas organizados en el interior del país a estar listos para levantarse en armas. ${ }^{14}$ La dirección del PLM insistía en llevar a cabo una batalla abierta en contra del régimen en el campo periodístico y en el terreno de la política a través de Regeneración, y una lucha clandestina con grupos secretos encargados de organizar una revolución armada constituidos en una amplia red que se extendía principalmente por los estados fronterizos de Texas, Nuevo México, Arizona y California en Estados Unidos, y Tamaulipas, Coahuila, Chihuahua y Sonora, del lado mexicano.

En dos años de actividad, la JopLm logró conformar una nutrida base social compuesta por trabajadores mexicanos, eventuales o residentes permanentes, en las poblaciones de la frontera, gracias a lo cual Ricardo Flores Magón estaba convencido de que este era el mejor lugar para iniciar una revolución, pues "nada hay tan mal resguardado como la frontera", ${ }^{15}$ un factor que le garantizaría al PLM contar con una retaguardia, así como una línea de abasto de víveres y armas necesarios para la revolución. Una vez que la insurrección estallara en distintos puntos del territorio nacional, el gobierno mexicano se vería obligado a dividir sus fuerzas militares y nuevas rebeliones desde el interior generalizarían la revolución. Pero ¿cómo habían surgido el apoyo social y las redes clandestinas del PLM en la frontera en tan solo dos años de actividad propagandística?

En los albores del siglo xx, México experimentó un auge industrializador en busca de la modernización de su economía. La industria metalúrgica alcanzó importantes niveles de producción

13 Fabela, 1965, pp. 36-39.

14 Utilizamos el concepto "pelemista" para referirnos a los integrantes y militantes del PLM, en lugar del término "magonista" usado tradicionalmente en la historiografía que estudia el tema. La acepción fue acuñada por Rubén Trejo (2005).

15 Flores Magón, 2001, p. 176. 
y llegó a representar 70 \% de las exportaciones totales del país, lo cual generó que, en torno a ella, naciera un proletariado de importantes dimensiones. Hacia 1907 había 97700 trabajadores ocupados en las minas, 75000 en la construcción y 50000 en transporte. El número de habitantes aumentó de 10 a 15 millones entre los años de 1885 y 1910. Sin embargo, a finales de la primera década del siglo, el país aún conservaba una población predominantemente rural que vivía en pésimas condiciones. ${ }^{16}$

Durante esta misma década, un número creciente de mexicanos de distintas procedencias geográficas se vieron obligados a migrar hacia Estados Unidos, no como consecuencia de la represión política, como había sido el caso de los liberales agrupados en el PLM, sino para escapar de las condiciones desfavorables en el campo, de la falta de empleo en la ciudad o de ingresos económicos insuficientes para su sostenimiento. El desarrollo capitalista del vecino país en determinados enclaves geográficos, y particularmente en la zona fronteriza, abrió mayores ofertas de trabajo, por lo cual se convirtió en un imán para aquellas personas que abandonaban sus lugares de origen. ${ }^{17}$

La expansión del capitalismo industrial en Estados Unidos determinó que, a lo largo de la frontera, se incrementara la necesidad de mano de obra barata para el trabajo no calificado, la cual fue proporcionada principalmente por trabajadores mexicanos, tanto locales como inmigrantes. Para un mexicano, emigrar a Estados Unidos no implicaba dificultad alguna gracias a la política de "puertas abiertas" del gobierno, que estableció medidas flexibles para permitir la entrada de inmigrantes, luego de reconocer la importancia de los trabajadores extranjeros en la dinámica industrial del país. ${ }^{18}$

16 Torres Parés, 1990, p. 41; Seminario de historia moderna de México, (s.f.), pp. 25-26, 46-60.

17 García y Griego y Verea, 1988, p. 56.

18 Aunque se establecieron algunas excepciones: entre 1882 y 1917 se creó y expandió una "lista de categorías de extranjeros no deseables; 'convictos', 'lunáticos', 'débiles mentales', 'epilépticos', 'limosneros', 'anarquistas', 'prostitutas', 'alcahuetes', 'analfabetas', personas 'susceptibles de convertirse en carga pública', y personas que tuvieran ciertas enfermedades" (García y Griego y Verea, 1988, p. 60). 
El despunte de la dinámica económica en esta zona comenzó a finales de la década de 1870, cuando el sur de Texas se conectó con el resto de Estados Unidos mediante cuatro líneas ferroviarias que llegaron hasta El Paso, lugar que evolucionó rápidamente de un pueblo menor de frontera a un centro de importancia internacional gracias a su ubicación geográfica, pues estaba directamente conectado por vía ferroviaria con las costas de los océanos Pacífico y Atlántico, pero también con el interior del país a través de diversos ramales que daban salida a la producción de origen texano y a las materias primas provenientes de México. En El Paso se manufacturaban una gran variedad de mercancías: maquinaria para la industria y la agricultura, materiales de construcción, artículos domésticos, ropa y un sinnúmero de productos de consumo; también era un importante centro ganadero, cementero y minero. Ahí se encontraba la sede principal de American Smelting and Refining Company (Asarco), desde donde se fundía, procesaba y distribuía el metal proveniente de las minas chihuahuenses y de otras regiones de México.

Además, la llegada del ferrocarril dio pie a la introducción de la agricultura comercial a gran escala; la producción algodonera texana aumentó considerablemente para satisfacer la demanda de una creciente industria textil: hacia 1890 el estado de Texas se convirtió en el primer productor de algodón del país; como señala Esparza Valdivia (2000), "precisamente este auge inició la inmigración de trabajadores mexicanos a Texas, donde trabajaban en la pizca de algodón en las proximidades de San Antonio". ${ }^{19}$ De esta manera, la región se volvió uno de los más importantes polos de abastecimiento de Estados Unidos. ${ }^{20}$

Gracias a esta diversidad económica, el estado de Texas comenzó a demandar una gran cantidad de trabajadores no especializados, lo cual fomentó la migración de mexicanos que se integraron a una amplia comunidad mexicana residente en la frontera texana. Don Coerver y Linda Hall (1995) refieren que, dada la "ausencia de un concepto auténtico de frontera", El Paso y Ciudad

19 Esparza Valdivia, 2000, p. 33.

20 Véase: Martínez, 1992, pp. 39-49.

Chimuahua Hoy, aÑo i6, Núm. I6 (ENERo-Diciembre, 2018) 
Juárez se constituyeron en "una unidad tanto geográfica como cultural y económica. El río Bravo era la única frontera natural utilizable para establecer los linderos internacionales, pero tampoco representaba una barrera física significativa”, ${ }^{21}$ lo cual fomentó el desplazamiento de trabajadores mexicanos hacia Estados Unidos. Con la llegada de una oleada de migrantes a la frontera, se estableció una cohesión social con los residentes estadounidenses de origen mexicano, pues, como señalan Gómez-Quiñones y Maciel (1999), "los inmigrantes transmiten, crean y recrean cultura. Constituyen comunidades tanto étnicas como espaciales" ${ }^{22}$ De esta manera, los estadounidenses de origen mexicano conservaron un lazo de unión con sus pares mexicanos que se desplazaban de uno y otro lado de la línea: "en general, el sentido de identidad del pueblo mexicano era fuerte: se consideraban mexicanos y de hecho lo eran, a pesar de que los separaba la frontera". ${ }^{23}$

No obstante, las condiciones laborales y de vida de los mexicanos avecindados en el estado de Texas eran muchas veces penosas e insalubres. La explotación laboral en los centros de trabajo impulsó a un número creciente de mexicanos a crear organizaciones mutualistas, logias masónicas y cooperativas de diferentes tipos y matices para protegerse de los abusos de que eran objeto, con un ánimo solidario y de apoyo mutuo frente a las arbitrariedades de los patrones estadounidenses y la discriminación racial; pero en la medida que estos grupos se comenzaron a relacionar con los exiliados llegados del centro de México, adquirieron poco a poco una nueva orientación ideológica y de clase, que fue reforzada paralelamente por la presencia de organizaciones como el Partido Socialista de Texas y las ramas locales de asociaciones sindicales de izquierda, como Industrial Workers of the World y Western Federation of Miners. ${ }^{24}$ El PLM tuvo un mayor impacto

21 Coerver y Hall, 1995, p. 19.

22 Gómez-Quiñones y Maciel, 1999, p. 52.

23 Ibid., p. 40.

24 A mediados de 1905 un grupo de obreros, mineros y madereros estadounidenses fundaron en la ciudad de Chicago la confederación Industrial Workers of the World (Iww), en la que confluyeron varios sectores de tendencia socialista y anarcosindicalista, cuyo objetivo era la politización de los trabajadores asalariados. Iww rápidamente se expandió hacia el suroeste de Estados Unidos y se convirtió en una opción para los 
entre la comunidad de migrantes gracias a que sus integrantes pudieron asimilarse fácilmente a la vida y al contexto cultural fronterizo, hablaban un mismo idioma y comprendían mejor que nadie las necesidades y aspiraciones de sus paisanos. Por ello, "cada pueblo era una sucursal del Partido Liberal. Los emigrantes mexicanos eran decididos partidarios de la revolución”. ${ }^{25}$

\section{CHIHUAHUA: SITUACIÓN SOCIAL, POLÍTICA Y ECONÓMICA}

Dentro de este contexto de agitación revolucionaria y movilidad social, el estado de Chihuahua presentaba una serie de condiciones excepcionales para los planes del PLM, debido a su condición fronteriza y a la situación política y social imperante en la primera década del siglo xx. Chihuahua se convirtió en una región prioritaria dentro del esquema militar y revolucionario ideado por la JOPLM, pues allí se encontraba una de las aduanas más importantes del país: Ciudad Juárez.

Conocida como Paso del Norte hasta 1888, Ciudad Juárez se convirtió en un punto fundamental del comercio internacional mexicano, lo cual posibilitó que el estado de Chihuahua alcanzara un dinamismo notable. Casi paralelamente al desarrollo ferroviario de Texas, al sur de la frontera el ferrocarril Central Mexicano instaló en Ciudad Juárez su terminal hacia el último cuarto del siglo XIX. Esta línea se convirtió en la columna vertebral del país, pues en 1884 permitió que el centro de México se enlazara con Estados Unidos, a través de la conexión de la capital de Chihuahua con

inmigrantes que no tenían cabida en otras organizaciones obreras de corte nacionalista que no admitían inmigrantes. Western Federation of Miners (WFM) era un sindicato industrial de corte socialista que brindó una alternativa sindical más a los mineros migrantes. Políticamente WFM era menos radical que Iww, pero era una aliada en la organización obrera anticapitalista; dicha central fomentó el sindicalismo revolucionario, propagó ideas socialistas a través de su órgano difusor The Miner's Magazine y también adoptó la práctica de la acción directa como forma de lucha política y económica, para exigir mejores condiciones laborales como la jornada de ocho horas y la elevación de los salarios. Véanse: Esparza Valdivia, 2000, p. 36; Taylor Hansen, 2001, pp. 316-317; Zamora, 1986, pp. 92-94, 128.

25 Valadés, 2010, p. 13. 
Ciudad Juárez y El Paso, cuyo tramo en esta última parte alcanzó una longitud de trescientos sesenta kilómetros.

El ferrocarril impulsó en la región un despunte mercantil que permitió que la producción local penetrara en el mercado nacional e internacional, lo cual posibilitó que la economía del estado se desarrollara y diversificara de manera significativa en los siguientes años, debido a las relaciones comerciales establecidas con el vecino país del norte. Particularmente fue importante la actividad minera, cuyos principales centros de extracción se encontraban en Parral, Minas Nuevas y Santa Bárbara, así como la ganadería extensiva. En 1897 el ferrocarril Río Grande, Sierra Madre y Pacífico conectó el municipio de Casas Grandes con Ciudad Juárez y El Paso, con una línea de doscientos kilómetros de extensión, gracias a la cual la zona de Casas Grandes, al noroeste del estado de Chihuahua, quedó unida de manera directa con la aduana de Ciudad Juárez-El Paso.

Esta apertura ferroviaria facilitó el proceso de modernización capitalista en la zona, pues, paralelas a las vías, se construyeron líneas telegráficas y toda una serie de industrias para satisfacer la demanda de materias primas, con lo cual el distrito Galeana se sumó al tren del progreso que en esos años avanzaba a velocidad acelerada. Jane-Däle Lloyd (1987) hace hincapié en el interés que despertaron en los grandes hacendados de Chihuahua los terrenos por los cuales corría el ferrocarril. Por ejemplo, entre 1898 y 1907 Luis Terrazas se enfocó en adquirir propiedades en Casas Grandes, debido a su conexión con Ciudad Juárez para el embarque de ganado; solo en Casas Grandes, las haciendas de Terrazas sumaban un total de 1250000 hectáreas. ${ }^{26} \mathrm{~A}$ finales del siglo xIX, el clan Terrazas logró amasar una enorme fortuna que lo llevó a convertirse en la potencia económica número uno del estado, cuya fortuna le permitió invertir en diferentes negocios y crear instituciones bancarias para diversificar su capital. De este proceso de expansión capitalista nació el banco Minero, el cual

26 González Herrera, 1986, p. 17. 
fungió en los siguientes años como el "cuartel general financiero del clan". ${ }^{27}$

El crecimiento económico del estado, se consolidó durante la administración de Enrique C. Creel en los seis años que estuvo al frente del gobierno de Chihuahua, entre 1904 y 1910, particularmente por la explotación minera y de recursos forestales. La oligarquía regional se benefició, en gran medida, de este proceso, debido a las facilidades y concesiones que el Gobierno del Estado otorgó a grupos locales; también se abrieron las puertas a la inversión de capitales norteamericanos, los cuales, de acuerdo con Jane-Däle Lloyd (1987), comenzaron a tener un peso mayor en el distrito Galeana: "por sus grandes extensiones de tierra, aptas para la ganadería, sus riquezas forestales y minerales, su activo comercio y su cercanía con la frontera, este distrito constituía un área ideal para la penetración económica de estos grupos”. ${ }^{28}$

Una de las compañías norteamericanas que se estableció en el distrito Galeana en 1885 fue Corralitos Land and Cattle Co., luego de que sus accionistas compraran al gobierno chihuahuense 140 400 hectáreas de tierra para ganado, extensión que aumentó en los siguientes años a 356265 hectáreas, debido a la adquisición de terrenos ejidales pertenecientes al municipio de Janos. Además, una compañía subsidiaria en El Sabinal compró 80000 hectáreas más; para el año de 1906, Corralitos Land and Cattle Co. se convirtió en la segunda compañía exportadora de ganado vacuno más importante del distrito. Estas tierras eran muy atractivas para las compañías ganaderas, debido a que el ferrocarril se había asentado en sus márgenes y facilitaba el transporte de sus reses hacia Estados Unidos.

Cabe señalar que el proceso de modernización capitalista en los estados mexicanos vinculados a enclaves mineros que satisfacían la creciente demanda de minerales para uso industrial, como cobre, hierro y carbón, implicó el incremento de necesidad de una mano de obra asalariada. Además de las minas, se establecieron fundidoras en Chihuahua para abaratar el costo de refinamiento 
de los metales industriales. La inversión extranjera posibilitó nuevas fuentes de trabajo, con atractivos salarios para los mexicanos en las compañías que tendían las líneas del ferrocarril y en los consorcios mineros cuyos sueldos eran los mejores del país.

No obstante la generación de empleos, las corporaciones norteamericanas se comportaban de manera racista con los trabajadores locales, reproduciendo en México las medidas aplicadas a los migrantes, pues los puestos de mayor jerarquía eran reservados para los extranjeros bajo el argumento de que, señala Robert Sandels (1975),

los trabajadores mexicanos, y en especial los indios, eran más difíciles de entrenar y menos eficientes. De esta manera justificaban las diferencias de sus sistemas de salarios, así como el rehusarse a contratar a los mexicanos para los trabajos más especializados. ${ }^{29}$

En las compañías ferrocarrileras estadounidenses, generalmente los mexicanos solo podían aspirar a ocupar puestos de peones, mozos o garroteros, y difícilmente el de maquinistas. ${ }^{30}$

Esta situación laboral le permitió al PLM penetrar en el naciente proletariado norteño, debido a que la dinámica propia del desarrollo capitalista estableció condiciones desventajosas de trabajo en las minas y la industria, estableciendo así un campo fértil para la agitación obrera, como había sucedido con los trabajadores migrantes que laboraban en las industrias estadounidenses. Jesús Vargas Valdés (2003) refiere que:

Los liberales del Distrito de Galeana conocían las ideas del Partido Liberal Mexicano que se difundían a través del periódico Regeneración; pero además esta región formaba parte de un corredor geográfico de trabajadores migratorios que transitaban periódicamente hacia las minas de Arizona y Nuevo México, donde el Partido Liberal

29 Sandels, 1975, p. 395.

30 Ruiz, 1978, p. 29; Martínez, 1992, p. 29. 
El Partido Liberal Mexicano y la insurrección Revolucionaria de 1906...

había logrado enraizar desarrollando una extensa base social que influía en varias poblaciones fronterizas de México. ${ }^{31}$

Los trabajadores mineros se convirtieron en uno de los bastiones más importantes de la propaganda liberal, pero no fueron los únicos, pues, "la mayoría de los integrantes del PLM en 1906 pertenecían a los sectores medios, [...] eran pequeños o medianos productores, con tierras propias y un poco de ganado". ${ }^{32}$ Entre la gama social de simpatizantes pelemistas también había comerciantes, vendedores, artesanos, cocheros, ferroviarios y oficinistas. $^{33}$ Los rancheros ${ }^{34}$ fueron otra importante fuerza de apoyo de los liberales en los siguientes años, cuando la expansión de las haciendas y compañías ganaderas hizo de ellos una fuerza potencial de disgusto e indignación como consecuencia de una serie de medidas implementadas por el gobierno estatal. Particularmente fue decisiva para el PLM la zona noroeste del estado: el distrito Galeana, que estaba conformado por los municipios de Casas Grandes, Janos, San Buenaventura, Galeana y La Ascensión, pues aquí se llevó a cabo con mayor intensidad un proceso de deslindamiento de tierras que benefició a los grandes propietarios en detrimento de los pueblos chihuahuenses.

Desde 1884 la ofensiva de las compañías deslindadoras "amparadas por el Estado mexicano” permitió que una importante cantidad de terrenos nacionales, que eran de uso común entre los rancheros pertenecientes a las antiguas colonias agrícolas militares chihuahuenses, fueran vendidos por el gobierno a los latifundios de propietarios extranjeros o de oligarcas locales. Pero el detonador del descontento entre los rancheros fue la implementación, a principios de 1905, de la Ley de Medida y Enajenación

31 Vargas Valdés, 2003, p. 54.

32 Lloyd, 1988, p. 40.

33 Altamirano, 1982, p. 33.

34 Jane-Däle Lloyd (1988, p. 78) define al ranchero de la siguiente manera: "un cultivador y ganadero rural, propietario o usufructuario individual o familiar de una parcela que participa en pequeña escala en una propiedad para un mercado local, regional y hasta internacional [ ] Cultural y socialmente está inmerso en una serie de relaciones de tipo directo, cara a cara, definidos por la familia extensa y por la comunidad. Participa activamente en la vida ceremonial de su barrio y de su comunidad". 
de Terrenos Municipales decretada por el gobierno de Enrique Creel, la cual autorizaba el deslinde y fraccionamiento inmediato de dichas propiedades. Esta disposición afectó de manera directa a los terrenos comunes y ejidales de los fundos legales que fueron vendidos a particulares, y anuló las restricciones de las Leyes de Desamortización del periodo de la Reforma, que protegían las tierras municipales de ser expropiadas. Con ello, se dio pie al acaparamiento de la tierra por parte de las personas con mayores recursos económicos para comprar, así como al surgimiento de grandes latifundios, a la vez que se eliminaba la libertad de disposición que los pequeños propietarios tenían sobre los recursos básicos de las tierras comunes. Como señalamos páginas atrás, el distrito Galeana fue uno de los primeros afectados por esta ley, particularmente los municipios de Casas Grandes y Janos, donde el deslinde y fraccionamiento de terrenos municipales permitió a la oligarquía local hacerse de una gran cantidad de tierras, además de polarizar a los diferentes estratos sociales de la región. ${ }^{35}$

El gobierno federal también intervino en este proceso en la región tras otorgarle al estadounidense Luis Huller autorización para colonizar una parte del pueblo de Palomas, al norte del municipio de Janos, por un total de 712000 hectáreas en el año de 1888, que fueron vendidas a nuevos inversionistas norteamericanos y pasaron posteriormente a formar parte de Palomas Land and Cattle Co. Esta última compañía siguió adquiriendo tierras hasta aumentar su extensión a 895050 hectáreas en 1906, luego de que ocupara las tierras pertenecientes a los pueblos de Janos y La Ascensión. ${ }^{36}$ Curiosamente, en Palomas Land and Cattle Co. las condiciones de trabajo eran mejores que en el promedio de las compañías extranjeras, pues allí se pagaba un peso diario a los vaqueros mexicanos más alimentos y medicinas; en las haciendas de Luis Terrazas, se les pagaba a los peones cincuenta centavos, salario que debía ser gastado en las tiendas de raya. ${ }^{37}$

35 Lloyd, 1987, p. 89.

36 Ibid., p. 84.

37 Lloyd, 1987, p. 84. 
En La Ascensión, la ley de 1905 permitió a los colonos mormones norteamericanos invadir las tierras de los rancheros locales. Por todo ello, en el distrito Galeana "se empezaron a formar los primeros núcleos magonistas en el área; incluso, los individuos y grupos sociales más directamente afectados por ella lla ley de 1905] fueron los que integraron la base social de dichos núcleos" ${ }^{38}$ Estos grupos fueron fundamentales para el PLM entre 1908 y 1910, luego de que varios habitantes de Casas Grandes y Janos decidieran tomar las armas por la causa de los liberales, motivados por las intensas disputas con los propietarios de las haciendas de Corralitos y Palomas.

El conflicto por la tierra comenzó a adquirir una mayor relevancia en la vida del ranchero en este tiempo; ellos, nos dice Jane-Däle Lloyd (1988), "eran los afectados directamente por el acaparamiento de los mormones y por su creciente injerencia en el pequeño comercio, que implicaba su paulatina marginalización del mercado local y regional" ${ }^{39}$ La concentración de tierras desató una intensa lucha contra la corrupción del gobierno que legalizó sistemáticamente la confiscación de tierras a los pueblos. Nuevamente, Jane-Däle Lloyd (1988) nos proporciona cifras contundentes al respecto:

A principios del siglo XX era abrumador el acaparamiento de tierras en el distrito de Galeana. Los extranjeros poseían alrededor del $56 \%$ del territorio total; Terrazas y otros miembros de la oligarquía se apoderaron aproximadamente del 40\%, o sea que cerca del 96\% del área total del distrito -las mejores tierras- se encontraban en manos de estos grupos. ${ }^{40}$

Este escenario llevó a varios agricultores a convertirse en medieros o trabajadores asalariados de las empresas norteamericanas o de las haciendas de los Terrazas. Sin contar con una fuente de sustento segura, muchos de ellos se vieron obligados a viajar

38 Lloyd, 1988, p. 79.

39 Ibid., p. 103.

40 Lloyd, 1988, p. 103.

Chimuahua Hoy, año i6, NúM. I6 (ENERo-Diciembre, 2018) 
hacia el norte para convertirse en trabajadores de las industrias minera o ferrocarrilera, o en "braceros" en los campos de cultivo. Entre 1905 y 1907, el auge económico e industrial en el vecino país permitió que se abrieran nuevas oportunidades de trabajo para los campesinos y rancheros venidos a menos. Como señalamos líneas atrás, una creciente demanda de mano de obra y mejores salarios posibilitaron alternativas de trabajo en los estados de Arizona, Nuevo México y Texas,

los salarios en los EE. UU. eran el doble de los de México, porque los patrones pagaban en oro en vez de en plata. Además, con frecuencia los trabajadores recibían alojamiento gratuito así como el transporte de ida y de regreso del trabajo, incluido en sus contratos. ${ }^{41}$

Otro factor a considerar es que el estado de Chihuahua experimentó un crecimiento del descontento social derivado de la monopolización y centralización del poder en todos los niveles de gobierno; desde la gubernatura del estado hasta las jefaturas municipales, los puestos públicos fueron cooptados por el clan Terrazas-Creel y sus allegados, proceso que implicó la pérdida de la autonomía municipal, principal característica de los pueblos libres del norte. ${ }^{42}$ El dominio político del clan, se combinó con su poder económico y financiero, pues, además de poseer millones de hectáreas de tierra, este grupo monopolizaba la banca del estado y tenía asegurado el control sobre los créditos. ${ }^{43}$. El aumento en los impuestos a los pequeños propietarios, fue otra de las medidas impopulares que se convirtió en la gota que derramó el vaso y provocó un descontento generalizado que fue aprovechado por el PLM, una vez que este grupo logró establecer una alianza multiclasista de obreros, campesinos y pequeños propietarios que se oponían tanto a la oligarquía local como al gobierno estatal. Los delegados pelemistas realizaron una labor de propaganda en varios pueblos

41 Wasseman, 1988, p. 188.

42 Katz, 1998, pp. 31-34.

43 Altamirano y Villa, 1988, pp. 170-171. 
El Partido Liberal Mexicano y la insurrección Revolucionaria de 1906...

y centros urbanos, donde fueron bien acogidos y encontraron simpatizantes dispuestos a sumarse a la causa. ${ }^{44}$

\section{LA INSURRECCIÓN EN MARCHA}

La intensa propaganda en la prensa, el activismo sindical, el flujo de migrantes en la frontera, las condiciones sociales y económicas del estado de Chihuahua, y un programa político como articulador del descontento generalizado permitieron a la JOPLM consolidar su plan para provocar una revolución armada en el país. Para llevar a cabo sus propósitos, el PLM estableció una estructura militar jerárquica elemental, apoyada en "una dirección central, un aparato clandestino y una red de correspondencias y de grupos locales" ${ }^{4}$ De acuerdo con Enrique Flores Magón y Samuel Kaplan (2006), ${ }^{46}$ la JOPLM convino dividir a la república en cinco zonas militares, las cuales estarían al mando de un delegado especial y un jefe de guerrillas, coordinados a su vez por un delegado general, quien debía viajar a todas las zonas de guerra para transmitir las órdenes de la JOPLM. El PLM contaba en 1906 con sesenta y siete núcleos armados posicionados en distintos puntos del país, de los cuales los estados de Chihuahua, Coahuila, Nuevo León, Sonora y Tamaulipas concentraban la mayor parte como consecuencia del crecimiento del proletariado industrial que operaba en los enclaves mineros; pero también al interior de la república existían grupos diseminados en Hidalgo, Michoacán, Nayarit, Oaxaca, San Luis Potosí, Sinaloa, Tabasco, Tlaxcala, Veracruz y Zacatecas. ${ }^{47}$

Las guerrillas que el PLM articuló estaban conformadas por un conglomerado multiclasista de trabajadores del campo y la ciudad, así como de pequeños propietarios y comerciantes, que de manera voluntaria se sumaron a la organización y generalmente eran quienes recibían las mayores responsabilidades políticas y militares: "los delegados políticos tendían a ser de un mejor nivel

44 Lloyd, 1988, p. 37; Aurrecoechea y Barrera, 1985, p. 101.

45 Guerra, 1988, p. 173.

46 Flores Magón y Kaplan, 2006, p. 152.

47 Lloyd, 1988, p. 37; Aurrecoechea y Barrera, 1985, p. 101; Hernández Padilla, 1988, p. 91; Valadés, 2006, p. 553. 
económico que los jefes de los núcleos armados y se dedicaban, en términos generales, a actividades económicas 'tácticamente móviles' como la arriería o el comercio ambulante”. ${ }^{48}$ El número de integrantes variaba de acuerdo con la influencia del PLM en cada zona de la república; podrían existir grupos de hasta trescientas personas, pero en la mayoría de los casos difícilmente excedieron los cincuenta miembros. No obstante, uno de los mayores problemas que enfrentó la dirección del PLM fue la falta de recursos económicos para el financiamiento de la insurrección, por lo cual esta giró instrucciones para que cada correligionario se valiera de sus propios medios para armarse, mientras que las guerrillas podrían expropiar fondos de las oficinas del gobierno una vez iniciados los levantamientos, lo que les daba a estas autonomía —capacidad propia de acción. ${ }^{49}$

El plan general que la JOPLM esbozó para insurreccionar al país consistía en realizar una serie de ataques sorpresa en las principales aduanas de la frontera, pues ello facilitaría a los grupos pelemistas la obtención de armas arrebatadas a los militares, además de financiamiento económico derivado del control comercial en la frontera. ${ }^{50}$ Paralelamente, se llevarían a cabo levantamientos simultáneos al interior de la república, con el objetivo de generalizar una oleada revolucionaria en todo el mapa mexicano:

Se están organizando focos rebeldes en todo el país; hay en la actualidad cuarenta grupos diversos, pero muchos de ellos están muy mal armados; nuestra principal preocupación es conseguir armas para equipar siquiera a treinta grupos, y entonces la junta dará la orden para que todos los focos revolucionarios se levanten al mismo tiempo. ${ }^{51}$

A finales de agosto de 1906, Ricardo Flores Magón y Juan Sarabia se trasladaron a El Paso, Texas, para coordinar desde allí las acciones que debían llevarse al otro lado de la frontera. No era

48 Lloyd, 1988, pp. 44-45.

49 Hart, 1980, p. 122; Hernández Padilla, 1988, p. 90.

50 Lloyd, 1988, p. 51.

51 Flores Magón, 2001, p. 198. 
fortuito que se eligiera El Paso como el centro de operaciones de la JoPLM, pues, como señalamos, allí se concentraba una gran parte de simpatizantes y, gracias a su conexión directa con Ciudad Juárez, era el lugar ideal para que la Joplm llevara a cabo sus planes de invasión.

Ciudad Juárez, además, era un punto medular en los planes militares del PLM: era la punta de lanza de la revolución, pues al ser uno de los puestos fronterizos más importantes del país, la aduana tenía una vital importancia geográfica y económica. Ocupar Ciudad Juárez significaba prácticamente tomar el control económico del estado, y también facilitaba el flujo de armas y de artículos de primera necesidad para la guerra; asimismo, le permitiría al movimiento revolucionario obtener una resonancia de magnitud internacional y la posibilidad de establecer una cabeza de playa para instaurar un gobierno provisional, con una salida segura hacia Estados Unidos en el caso de una derrota y su consecuente repliegue. Desde Ciudad Juárez los revolucionarios pelemistas tratarían de expandirse hacia el sur, mientras se generalizaba la insurrección. Ciudad Juárez era, pues, la llave de acceso que le permitiría a la JOPLM ingresar desde Estados Unidos a la revolución en México.

La actividad político-militar de la JOPLM en Texas vino a reforzarse con el ingreso al grupo de Lauro Aguirre, un periodista de oposición y activista con un largo camino recorrido, quien desde El Paso editaba periódicos críticos en contra del régimen de Porfirio Díaz. Aguirre era un personaje carismático con una agitada trayectoria, pues tenía varios antecedentes en su historial revolucionario: en 1891 se relacionó con Teresa Urrea, la Santa de Cabora, y con los rebeldes de Tomóchic; en 1896 participó en un intento insurreccional en la aduana de Palomas encabezado por Demetrio Cortés y Prisciliano Silva; posteriormente, acompañó y cobijó a Teresa Urrea cuando las autoridades mexicanas la obligaron a exiliarse en Estados Unidos. La Santa se había establecido en Clifton, Arizona, donde cientos de mexicanos iban en su búsqueda para ser atendidos por ella, dadas sus dotes curativas y milagrosas, hasta que finalmente mudó su residencia a El Paso, 
Texas. Cuando Teresa Urrea murió en 1906, Aguirre se incorporó al pLM gracias a la creciente influencia que este grupo había adquirido en la zona; al vincular a esta organización su red de apoyo social y sus medios de propaganda, Aguirre se convirtió en uno de los brazos de soporte fundamentales del plm en Texas en los siguientes dos años. ${ }^{52}$

En las oficinas de La Reforma Social, periódico editado por Lauro Aguirre, se fraguó la conspiración revolucionaria de la JoPLM; fue allí donde se reunió la dirección del PLM con los militantes de Ciudad Juárez y El Paso para organizar el contrabando de armas de las futuras acciones militares. El ambicioso plan de invasión que la Joplm estableció para conquistar Ciudad Juárez consistía en cruzar con botes el río Bravo desde El Paso, tomar por asalto la aduana y el cuartel militar tratando de volar con dinamita sus barracas, ocupar los puntos estratégicos de la ciudad, expropiar el dinero de los bancos y las armas de los cuarteles policiacos, tomar las locomotoras del ferrocarril Central Mexicano y avanzar hacia el sur, con una escala obligada en la casa del general Luis Terrazas en Chihuahua para hacerla estallar. Antonio Villarreal y Juan Sarabia se encargarían de organizar la insurrección del lado mexicano, mientras que otro grupo repartido en las casas de Lauro Aguirre y Prisciliano Silva avanzaría desde Estados Unidos para apoyar a los rebeldes. Además, la joplm tenía previsto que Antonio de Pío Araujo insurreccionara en Sonora a los militantes del PLM para tomar las aduanas de Agua Prieta y Nogales con el apoyo de los pelemistas de Arizona, mientras que Jesús María Rangel haría lo propio en la frontera de Coahuila, repitiendo el esquema planeado para Ciudad Juárez. ${ }^{53}$

La fecha tentativa para que estallara la insurrección, se estableció entre septiembre y octubre, meses en los que se levantaba la cosecha agrícola, lo cual les garantizaría a los rebeldes el abasto de alimentos y recursos económicos para sostener una campaña

52 Torres Parés, 1990, p. 68; Martínez Núñez, 1965, p. 153; Valadés, 2006, p. 148; Vargas Valdés, 2014, p. 24.

53 Hernández Padilla, 1988, p. 95; Cosío Villegas, 1974, p. 341; Martínez Núñez, 1965, p. 153; Altamirano, 1982, p. 36; Valadés, 2010, p. 7. 
revolucionaria exitosa. ${ }^{54}$ La JOPLM propuso en primera instancia el 16 de septiembre, debido a la carga simbólica y representativa de la fecha, aunque finalmente debió posponerse, pues la dirección pelemista consideró que se necesitaría un mes más de preparación para el levantamiento armado.

No obstante la actuación sigilosa del PLM para insurreccionar al país, sus planes fueron conocidos por las autoridades estadounidenses y mexicanas luego de que el 5 de septiembre de 1906 la policía de Douglas desmantelara el núcleo insurreccional de Arizona, tras asaltar los escondites y depósitos de armas de los pelemistas establecidos en la frontera de Arizona, lo cual les permitió decomisar documentos y correspondencia comprometedora que los puso sobre la pista de las actividades secretas de la JOPLM. Desde la Ciudad de México, el vicepresidente Ramón Corral giró instrucciones a Enrique C. Creel para que extremara precauciones y evitara un brote de violencia en su estado, recomendándole que se pusiera en contacto con las autoridades de Texas para capturar a los revoltosos, y sugería "estimularlas de alguna manera eficaz, aun cuando resulte costosa, para que ayuden con buena voluntad". ${ }^{55}$ Investigaciones policiacas posteriores realizadas por Creel señalaron que el PLM tenía diversas ramificaciones en el territorio chihuahuense,

especialmente en las regiones del centro, oriente y sur del estado, a lo largo del ferrocarril y en la sierra [...] Ciudad Jiménez, Ciudad Camargo, Santa Rosalía, Casas Grandes, Minas Nuevas y Bachíniva son sólo algunos de los puntos de implantación del movimiento liberal. ${ }^{56}$

Las acciones policiacas preventivas lograron disuadir a los grupos que se preparaban en el interior del país y provocaron que la JOPLM perdiera la coordinación con ellos al interferir en sus comunicaciones. No obstante el desmantelamiento de varios grupos revolucionarios, se llevaron a cabo dos levantamientos en la fron-

54 Flores Magón, 2001, p. 176.

55 Carta de Ramón Corral a Enrique C. Creel, México, 9 de octubre de 1906, en Torres Parés, 1990, p. 49.

56 Torres Parés, 1990, p. 52. 
tera; el primero sucedió en Ciudad Jiménez, Coahuila, cuando una treintena de liberales comandados por Juan José Arredondo y León Ibarra invadieron el pueblo desde Eagle Pass el 26 de septiembre, protagonizando con ello el primer acto de armas del PLM; el grupo fue derrotado y obligado a dispersarse al otro lado de la frontera. Un segundo levantamiento sucedió en Acayucan, Veracruz, el 30 de septiembre, donde trescientos campesinos mal armados de San Pedro Soteapan, comandados por Hilario C. Salas y Cándido Donato Padua, intentaron tomar la plaza con resultados similares a los de sus compañeros en el norte. El resto de los grupos del interior no fueron puestos sobre aviso y, en consecuencia, no pudieron actuar a tiempo para secundar y generalizar la rebelión. ${ }^{57}$

A pesar de los fracasos armados en Coahuila y Veracruz, la joPLM decidió llevar a cabo sus planes originales para tomar Ciudad Juárez, una acción ejemplar que los miembros del PLM consideraban debía ser la chispa que encendiera la revolución en el país. No obstante, nuevamente la policía de Chihuahua se encontraba un paso adelante de la JOPLM; la información recabada por las autoridades de ambos países, permitió conocer con detalle los planes de la Joplm, de acuerdo con los informes que Enrique C. Creel enviaba a Porfirio Díaz:

En el Paso, Texas, existe un centro revolucionario encabezado por Lauro Aguirre, que está activando mucho sus trabajos. Tiene reuniones todas las noches. Se cree que Magón o Sarabia está escondido en El Paso. Está solicitando gente para dar algún golpe. Creo conveniente que general Vega vaya a Ciudad Juárez a vigilar al enemigo y a infundir respeto. ${ }^{58}$

Creel dispuso infiltrar al grupo de Ciudad Juárez a dos militares que se pusieron en contacto con los conspiradores, ofreciéndoles sus servicios para la causa del PLM, a través de los cuales el gobernador logró obtener cada pormenor de los planes revolucio-

57 Brown, 1956, p. 130; Hernández Padilla, 1988, p. 93; Valadés, 2006, p. 165; Barrera Fuentes, 1973, p. 98.

58 Carta de Enrique C. Creel a Porfirio Díaz, Chihuahua, 4 de octubre de 1906, en Valadés, 2006, p. 167. 
narios. ${ }^{59}$ Con esta información las fuerzas de seguridad en Chihuahua desmantelaron a los pelemistas de Ciudad Juárez mediante golpes quirúrgicos, rápidos y silenciosos. El 19 de octubre Juan Sarabia, César Canales y Vicente de la Torre fueron arrestados en Ciudad Juárez cuando ultimaban los detalles para el asalto desde el lado mexicano, mientras que en El Paso fueron hechos prisioneros Antonio Villarreal, Lauro Aguirre y varios conspiradores más; Ricardo Flores Magón, que esperaba a sus camaradas en la línea fronteriza, al percatarse de las detenciones de sus compañeros logró escapar para ponerse a salvo en territorio estadounidense.

En El Paso fueron cateadas y desmanteladas las oficinas del PLM, donde se encontraron varios documentos que comprometían a los grupos armados en Chihuahua y en el resto del país, información que ayudó nuevamente a la policía para proceder a desmantelar los centros conspirativos en los siguientes días, como el Club Liberal Benito Juárez de Hidalgo del Parral, el cual estaba encabezado por Élfego Lugo. ${ }^{60}$ Por su parte, Ricardo Flores Magón se vio obligado a huir hacia California para ponerse a salvo de la persecución policiaca, mientras que Antonio Villarreal y Lauro Aguirre lograron fugarse de la prisión a principios de 1907.

Pero Juan Sarabia no corrió con la misma suerte y fue enviado a la terrible prisión de San Juan de Ulúa, junto con un número importante de correligionarios como castigo ejemplar a su actividad revolucionaria. Durante su juicio, llevado a cabo en la ciudad de Chihuahua en enero de 1907, Sarabia hizo una brillante defensa de su persona frente a los jueces que lo juzgaron, con argumentos que justificaban su actuación, tanto periodística como revolucionaria, en contra de la dictadura:

La publicación de mi impreso revolucionario, lo mismo que el más sangriento de los combates, forman por igual, parte de una rebelión y son inherentes a ella; pues nunca se ha visto, ni se verá probablemente, que exista una revolución sin que haya propaganda de idea,

59 Brown, 1956, p. 133.

60 Barrera Fuentes, 1973, p. 99. 
como preliminar, y derramamiento de sangre como medio inevitable para decidir la suerte de la empresa. ${ }^{61}$

Sarabia y sus compañeros no recobrarían su libertad sino hasta el triunfo de la revolución maderista, en mayo de 1911

El 30 de octubre de 1906, Enrique C. Creel telegrafió a Porfirio Díaz el siguiente mensaje: "De las personas comprometidas en Chihuahua, han sido aprehendidas hasta el último. Falta ahora limpiar otros estados". ${ }^{2}$ A partir de este momento, Creel comenzó a ser una pieza fundamental en el engranaje de seguridad del gobierno mexicano, ya fuera como garante de la frontera de su estado - la más convulsionada por la actividad pelemista desde Texas - o como eventual embajador mexicano ante el gobierno de Estados Unidos, encargado de gestionar acuerdos y apoyos en contra de los disidentes exiliados. Creel coordinaba, además, junto con la Secretaría de Relaciones Exteriores, el sistema de espionaje que se encargó de vigilar estrechamente a los "revoltosos". Para explicar la violencia desatada en la frontera, que comenzó a preocupar seriamente al gobierno mexicano, Enrique C. Creel envió una carta a Ramón Corral, donde le manifestaba lo siguiente:

El hecho es tanto más notable, cuando que se trata de gente pobre, sin recursos, y que si se hubiera tratado de que pagasen 25 centavos de contribución al Gobierno, se habrían dejado embargar y habrían levantado el grito en el cielo, y no obstante, muchos de ellos, han privado del pan a sus hijos, para enviarle \$5.00 a los Flores Magón. Es digno de estudio este fenómeno social y político, por los efectos que produce sobre ciertas clases de la sociedad. ${ }^{63}$

El diagnóstico de Creel era acertado. ¿Qué orillaba a esa gente pobre a apoyar al PLm? El fenómeno social al que Creel hace referencia estaba determinado, por una parte, por las circunstancias económicas de la frontera, donde existían cientos de trabajadores

61 Citado por Morales Jiménez, 1960, p. 46.

62 Telegrama de Enrique C. Creel a Porfirio Díaz, Chihuahua, 30 de octubre de 1906, en Abad de Santillán, 1988, p. 45.

63 Carta de Enrique C. Creel a Ramón Corral, Chihuahua, 26 de noviembre de 1906, en Torres Parés, 1990, p. 53. 
migrantes expulsados de sus lugares de origen, pero también por la intensa propaganda del PLM que transmitió en este sector la idea de un cambio redentor establecido en su programa, sin olvidar el cúmulo de agravios sociales que se habían acumulado durante los primeros años de la administración Creel, lo cual propició un terreno fértil para la revolución propuesta por la JOPLM.

No obstante, la maquinaria represiva del gobierno chihuahuense resultó ser eficaz para atacar a los revolucionarios. A raíz de los fracasos armados y de los operativos policiacos en contra de la JOPLM, Regeneración se suspendió indefinidamente. Un panorama sumamente gris comenzó a vislumbrarse al interior de la JOPLM en los últimos meses de 1906, pero, en palabras que definirían la trayectoria del PLM en el transcurso de los siguientes cuatro años, Enrique Flores Magón señaló: "Hemos sufrido grandes golpes, pero esto no deberá amilanarnos, al contrario, esto deberá irritarnos y hacernos más indomables". ${ }^{4}$

Así concluyó el año, con una serie de fracasos estrepitosos para el PLM, el cual había sufrido sus primeras derrotas. Correligionarios importantes del primero y segundo niveles en la estructura de la JOPLM habían sido arrestados, tanto en territorio nacional como en el estadounidense, como Juan Sarabia, vicepresidente de la Junta y uno de los más fervientes impulsores de la lucha armada, mientras que otros se vieron obligados a pasar a la clandestinidad, como el propio Ricardo Flores Magón, quien escapó hacia Los Ángeles, California, para refugiarse ahí en espera de mejores tiempos.

No obstante dichos fracasos, la semilla de la revolución se había sembrado en Chihuahua y la frontera. En los próximos meses el PLM volvería a retomar su proyecto insurreccional gracias a la incorporación de nuevos adeptos que se sumaron a su causa, entre ellos, Práxedis G. Guerrero, quien se convertiría en uno de los más destacados dirigentes revolucionarios de la JOPLm en los próximos años y le daría continuidad al proyecto insurreccional del PLm hasta 1910, cuando estalló la revolución maderista.

64 Carta de Enrique Flores Magón a Tomás Sarabia [s. 1.], 25 de octubre de 1906, en González Ramírez, 1964, p. 80. 


\section{CONCLUSIONES}

Además de ser considerados como los "precursores intelectuales de la Revolución Mexicana", los miembros del PLM tuvieron una participación destacada en la confrontación armada en contra de la dictadura de Porfirio Díaz, y no solo como difusores de ideas. Desde 1904 este grupo había llegado a la conclusión de que la única vía posible para transformar al país, era a través de la lucha armada, pues la vía política legal se había cerrado de manera arbitraria, por lo cual los pelemistas volcaron sus esfuerzos a consolidar sus planes revolucionarios, acompañándolos de un amplio proyecto nacional social, político y económico que involucró las opiniones y aspiraciones de sus militantes. La creación de una amplia red de comunicación, a partir de la distribución del periódico Regeneración, les permitió construir una red de apoyo dispuesta a secundar sus planes, particularmente en la frontera méxico-estadounidense, donde la migración mexicana era numerosa y acogió con simpatía al PLM.

En Chihuahua, el PLM encontró una mayor fuerza de apoyo no solo por la cercanía geográfica de este estado con la frontera estadounidense, sino por las condiciones sociales y políticas adversas por las que la población atravesó en la primera década del siglo xx, las cuales se amalgamaron con la actividad revolucionaria pelemista y la posibilidad de transformación política que este grupo les ofrecía a través de su programa. Por ello, el estado de Chihuahua fue fundamental para los planes militares del PLM, con Ciudad Juárez como uno de los objetivos prioritarios de la revolución.

Ciudad Juárez se convirtió en la punta de lanza de la revolución pelemista, debido a su importancia estratégica: era la llave que le daría acceso a la JoPLM de ingresar al territorio nacional y consolidar materialmente la lucha armada en contra de la dictadura, debido a la trascendencia económica de este puerto fronterizo. Por ello, la dirección del PLM se trasladó hasta El Paso, con la intención de encabezar la revolución en Ciudad Juárez, para, posteriormente, avanzar en línea recta hacia la capital del país. No obstante, los trabajos de inteligencia del gobierno mexicano 
permitieron conocer puntualmente los planes insurreccionales de la JopLM, lo cual les permitió llevar a cabo golpes quirúrgicos para desmantelar a sus grupos de apoyo y evitar así el estallido revolucionario planeado por el PLM.

A pesar de que la Joplm no logró sus objetivos y resultó fuertemente golpeada en su primera confrontación armada en contra de la dictadura, este grupo no cejó en sus actividades revolucionarias y hasta 1910 continuó con sus planes insurreccionales, siempre con Chihuahua como uno de los ejes fundamentales de la lucha armada. No fue fortuito que, cuatro años después, la revolución maderista encontrara en este estado su mayor fuerza de apoyo, y que Ciudad Juárez le haya otorgado a los antirreeleccionistas la victoria final frente a la dictadura. El PLM sabía del valor social y estratégico del estado, y por ello continuó priorizando la revolución en esta región en los años que siguieron a 1906.

\section{REFERENCIAS}

Abad de Santillán, D. (1988). Ricardo Flores Magón: el apóstol de la revolución social mexicana. México: Ediciones Antorcha.

Altamirano, G. (1982). Movimientos sociales en Chihuahua, 19061912. La Revolución en las regiones (Memorias) (T. I). Guadalajara: Universidad de Guadalajara.

Altamirano, G., \& Villa, G. (Comps.) (1988). Chihuahua: una historia compartida, 1824-1921. México: Gobierno del Estado de Chihuahua/Instituto de Investigaciones “Dr. José María Luis Mora".

Aurrecoechea, J. M., \& Barrera B., J. (1985). Las jornadas insurreccionales. Así fue la Revolución mexicana (T. I). México: Secretaría de Educación Pública.

Barrera Fuentes, F. (1973). Historia de la Revolución mexicana: la etapa precursora. México: Talleres Gráficos de la Nación.

Bartra, A. (1994). Regeneración, 1900-1918. La corriente más radical de la Revolución mexicana de 1910 a través de su periódico de combate. México: Ediciones Era. 
Brown, L. C. (1956). Los liberales mexicanos y su lucha en contra de la dictadura de Porfirio Díaz, 1900-1906. Antología MCC. México: El Colegio de México.

Cockcroft, J. D. (1981). Precursores intelectuales de la Revolución mexicana, 1900-1913. México: Siglo XXI Editores.

Coerver, D., \& Hall, L. (1988). Texas y la Revolución mexicana. Un estudio sobre la politica fronteriza nacional y estatal, 19101920. México: Fondo de Cultura Económica.

----- (1995). Revolución en la frontera. México: Consejo Nacional para la Cultura y las Artes.

Cosío Villegas, D. (1974). Historia moderna de México. El Porfiriato. La vida política exterior (2. ${ }^{a}$ parte, Vol. vI). México: Editorial Hermes.

Delgado González, A. (1991). El magonismo: la corriente radical y libertaria de la Revolución mexicana. México: Ediciones Quinto Sol.

Esparza Valdivia, R. C. (2000). El fenómeno magonista en México y en Estados Unidos, 1905-1908. México: Universidad Autónoma de Zacatecas-Centro de Investigaciones Históricas.

Fabela, I. (1965). Documentos históricos de la Revolución mexicana. Actividades politicas y revolucionarias de los hermanos Flores Magón (T. x). México: Editorial Jus.

Flores Magón, E., \& Kaplan, S. (2006). Peleamos contra la injusticia (T. I). México: Sindicato de Trabajadores de la Industria de la Radiodifusión, Televisión, Telecomunicaciones, Similares y Conexos de la República Mexicana.

Flores Magón, R. (2001). Correspondencia 1 (1899-1918). México: Consejo Nacional para la Cultura y las Artes.

García y Griego, M., \& Verea Campos, M. (1988). México y Estados Unidos frente a la migración de indocumentados. México: Coordinación de Humanidades de la unAm/Miguel Ángel Porrúa.

Gómez-Quiñones, J., \& Maciel, D. R. (1981). Al norte del río Bravo (1600-1930). La clase obrera en la historia de México. (Vol. xvI). México: Siglo XXI Editores/Instituto de Investigaciones Sociales de la UNAM. 
El Partido Liberal Mexicano y la insurrección Revolucionaria de 1906...

----- (1999). Polvos de aquellos lodos. Prácticas políticas y respuesta cultural en la internacionalización del trabajo mexicano, 1890-1997. En D. R. Maciel, \& M. Herrera-Sobek (Coords.), Cultura al otro lado de la frontera: inmigración mexicana y cultura popular. México: Siglo XXI Editores.

González Herrera, C. (1986). Las consecuencias de un auge o los antecedentes de una revolución. La Revolución en las regiones (Memorias) (T. I). Guadalajara: Universidad de Guadalajara.

González Ramírez, M. (1964). Epistolario y textos de Ricardo Flores Magón. México: Fondo de Cultura Económica.

Guerra, F.-X. (1988). México: del antiguo régimen a la Revolución (T. II). México: Fondo de Cultura Económica.

Hart, J. M. (1980). El anarquismo y la clase obrera mexicana, 18601931. México: Siglo XXI Editores.

Hernández Padilla, S. (1988). El magonismo: historia de una pasión libertaria, 1900-1922. México: Ediciones Era.

Katz, F. (1998). Pancho Villa (T. I). México: Ediciones Era.

Lloyd, J.-D. (1987). El proceso de modernización capitalista en el noroeste de Chihuahua (1880-1910). México: Universidad Iberoamericana.

----- (1988). Rancheros y revoluciones en el noroeste de Chihuahua/Los levantamientos del PLM en 1906. Historia de la cuestión agraria mexicana: campesinos, terratenientes y revolucionarios, 1910-1920 (Vol. II). México: Siglo XXI Editores/Centro de Estudios Históricos del Agrarismo en México.

Martínez, Ó. J. (1992). Ciudad Juárez: el auge de una ciudad fronteriza a partir de 1848. México: Fondo de Cultura Económica. Martínez Núñez, E. (1965). Juan Sarabia: apóstol y mártir de la Revolución mexicana. México: Instituto Nacional de Estudios Históricos de la Revolución Mexicana.

Morales Jiménez, A. (1960). Hombres de la Revolución mexicana: 50 semblanzas biográficas. México: Instituto Nacional de Estudios Históricos de la Revolución Mexicana.

Quevedo Rivero, A. (2000). Los colorados. México: Editorial Diana. Ruiz, R. E. (1978). La Revolución mexicana y el movimiento obrero, 1911-1923. México: Ediciones Era. 
Sandels, R. (Enero-Marzo 1975). Antecedentes de la Revolución en Chihuahua. Historia Mexicana 95 (Vol. xxiv, núm. 3). México: El Colegio de México.

Seminario de Historia Moderna de México (s.f.). Estadísticas económicas del Porfiriato: fuerza de trabajo y actividad económica por sectores. México: El Colegio de México.

Taylor Hansen, D. L. (2001). El magonismo en la región fronteriza de Sonora-Arizona (1910-1913). En M. Ceballos Ramírez (Coord.), Encuentro en la frontera: mexicanos y norteamericanos en un espacio común. México: El Colegio de MéxicoCentro de Estudios Históricos.

Torres Parés, J. (1990). La Revolución sin frontera. El Partido Liberal Mexicano y las relaciones entre el movimiento obrero de México y el de Estados Unidos, 1900-1923. México: Facultad de Filosofía y Letras de la UnAM.

Trejo, R. (2005). Magonismo: utopía y revolución, 1910-1913. México: Cultura Libre.

Valadés, J. C. (2006). La Revolución y los revolucionarios. (T. I, parte I: La crisis del Porfirismo. México: Instituto Nacional de Estudios Históricos de las Revoluciones de México.

---- (2010). Jesús María Rangel: el brazo armado del magonismo fronterizo. México: Para Leer en Libertad, A. C./Partido de la Revolución Democrática.

Vargas Valdés, J. (2003). Máximo Castillo y la Revolución en Chihuahua. Chihuahua: Nueva Vizcaya Editores.

---- (2014). Práxedis G. Guerrero y la otra revolución posible. México: Para Leer en Libertad, A. C.

Wasseman, M. (1988). Los orígenes sociales de la Revolución de 1910 en Chihuahua. En G. Altamirano, \& G. Villa (Comps.), Chihuahua: textos de su historia, 1824-1921 (Vol. 3). México: Gobierno del Estado de Chihuahua/Instituto de Investigaciones “Dr. José María Luis Mora”/Universidad Autónoma de Ciudad Juárez.

Wickstrom, S. (2011). The Border: los magonistas, prensa revolucionaria en los Estados Unidos y la trayectoria oculta de una revista de la frontera. En S. Jara Guerrero, C. Vélez-Ibáñez, 
El Partido Liberal Mexicano y la insurrección Revolucionaria de 1906...

R. Sánchez Benítez, \& H. Pérez Pintor (Coords.), Identidades transfronterizas: migración y cultura chicana. México: Plaza y Valdés Editores.

Zamora, E. (1986). El movimiento obrero mexicano en el sur de Texas, 1900-1920. México: Secretaría de Educación Pública. 